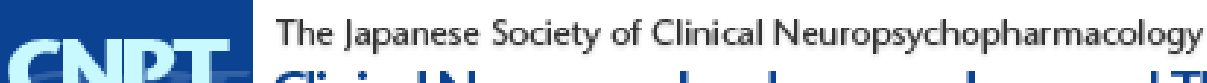 Clinical Neuropsychopharmacology and Therapeutics
}

\section{TEMPS-A/MPT as a quick finder for individualized treatments, including those targeting soft bipolarity}

\author{
Munenaga Koda, M.S., Tsuyoshi Kondo, M.D., Ph.D. \\ Department of Neuropsychiatry, Faculty of Medicine, \\ University of the Ryukyus, Okinawa, Japan
}

\begin{abstract}
Purpose: Affective temperaments have been suggested to predispose individuals to mood disorders, which can modify their psychopathology and response to treatment. This study aimed to obtain background data on the distributions of and associations among the temperaments, together with their relationships to age and gender, in non-clinical Japanese subjects.

Methods: The brief version of the Temperament Evaluation of Memphis, Pisa, Paris and San Diego-autoquestionnaire (TEMPS-A) and the Munich Personality Test (MPT) were administered to 278 healthy volunteers (154 males and 124 females 18-63 years of age). The former contains 39 questions assessing cyclothymic, hyperthymic, irritable, anxious and depressive temperaments, whereas the latter consists of 16 items measuring schizoid and melancholic type temperaments.

Results: The proportions of dominant temperaments (greater than the mean $+2 \mathrm{SD}$ ) were $6.1 \%$ for depressive, 3.6\% for cyclothymic and schizoid, $2.9 \%$ for irritable and anxious, $2.5 \%$ for melancholic, and $1.8 \%$ for hyperthymic. Strong correlations were found among four temperaments -- cyclothymic, irritable, depressive and schizoid ( $r s>0.5$, except for a value of 0.435 for the schizoid-depressive correlation) -- while hyperthymic, anxious and melancholic temperaments had modest satellite linkages with these four core temperaments. Age was moderately correlated with cyclothymic temperament ( $\mathrm{rs}=$ $-0.355, \mathrm{p}=0.001$ ) and weakly correlated with melancholic, depressive and irritable temperaments. Females were more likely to have cyclothymic and anxious temperaments, while males were more likely to have hyperthymic and schizoid temperaments.

Discussion: Close correlations among temperaments suggest that individualized treatment strategies should be implemented depending on the psychopathology of the individual, which could be affected by combined temperaments. Young and female individuals are more likely to have cyclothymic temperaments, suggesting that these subjects should be more likely to exhibit bipolarity.
\end{abstract}

Keywords: TEMPS-A, MPT, soft bipolarity, temperament, age, gender

Received April 21, 2010 / Accepted May 14, 2010 / Published October 1, 2010

\section{INTRODUCTION}

Although mood disorders have been usually categorized into depressive disorders and bipolar disorders $[1,2]$, there exists a considerable number of patients in a gray zone between these two distinct diagnostic categories. "The bipolar spectrum" proposed by Akiskal [3] provides a concept of continuity bridging unipolar depression and bipolar disorders. The author and colleagues [4] have further suggested that some

Corresponding Author: Tsuyoshi Kondo, MD, PhD, Department of Neuropsychiatry, Faculty of Medicine, University of the Ryukyus, 207 Uehara, Nishihara, Okinawa 903-0215, Japan

Tel:+81-98-895-1157 Fax:+81-98-895-1419 e-mail: kondo@med.u-ryukyu.ac.jp 
subaffective traits such as cyclothymic and hyperthymic temperaments should also be regarded as softer clinical expressions of bipolarity. Ghaemi et al [5] have heuristically defined non-spontaneous bipolarity accompanied by prevailing features of major depressive episodes as "bipolar spectrum disorder", where hyperthymic personality has been included as one item of a minor criterion. They also warned of the overuse of antidepressants in contrast to the underuse of mood stabilizers in subjects with bipolar spectrum disorder. These reports suggest that premorbid temperament/ personality is at least partly associated with vulnerability to mood disorders containing potential bipolarity, which can modify the psychopathology of the mood disorders and the treatment response to pharmacotherapy or psychotherapy.

Kraepelin [6] described four "fundamental states" of manic depressive illness. Based on these enduring subclinical states, without the florid symptoms, the Temperament Evaluation of Memphis, Pisa, Paris and San Diego-autoquestionnaire (TEMPS-A) was developed as a probe for the assessment of affective temperaments such as depressive, cyclothymic, irritable and hyperthymic temperaments [7]. Recently, the short version of the 39-item TEMPS-A, which includes an anxious element as the fifth factor, has been validated [8]. Apart from the measurements of these subaffective traits, Von Zerssen and colleagues [9] proposed the Munich Personality Test (MPT) to examine other aspects of personality traits, such as schizoid temperament [10], based on its isolationesoteric subscales, and melancholic type [11], based on its rigid tendencies.

In Japan, Akiyama and colleagues [12] proposed the combined model of TEMPS-A and MPT (TEMPS-A/MPT), and reported that this model was useful for comprehensive understanding of temperament/personality in Japanese subjects, including mood disorder patients. Factor analysis using TEMPS-A/MPT revealed 6 independent factors: cyclothymic, hyperthymic, irritable, melancholic, depressive, and schizoid temperaments. The reliability and validity of the original version of the 110-item TEMPS-A translated into Japanese have already been established in the Japanese non-clinical population and unipolar/bipolar patient groups [13]. Although there were significant correlations among depressive, cyclothymic, irritable, and anxious temperaments in both the control and patient groups, only hyperthymic temperament was independent of these 4 affective temperaments [13]. However, there are no available data on the relationships between these affective temperaments assessed by TEMPS-A and non-affective schizoid temperament or melancholic type as a premorbid temperament for unipolar depression in Germany or Japan measured by MPT [11]. Furthermore, these temperamental components as combined have not as yet been theoretically categorized from the standpoint of such clinically useful dichotomies as unipolarity/bipolarity and adaptation/maladaptation.

In order to examine the usefulness of TEMPS-A/ MPT as a quick finder for individualized treatments, including those targeting soft bipolarity, this study aimed to obtain background data on the distributions of and associations among affective and nonaffective temperaments, together with their relationships to age and gender, in non-clinical Japanese subjects.

\section{MATERIALS AND METHODS}

\section{Subjects}

Two-hundred seventy-eight non-clinical Japanese subjects (154 males and 124 females) were enrolled in the present study. The mean age $( \pm \mathrm{SD})$ was 33.7 $( \pm 10.0)$, and the age range was from 18 to 63 (teens: 23, twenties: 79: thirties: 102, forties: 51 , fifties or older: 23). The occupation of the subjects consisted of 112 company workers, 57 college/university students, 50 administrative officers, 48 medical/ comedical experts and 11 others. None were being treated for psychiatric diseases.

All subjects gave written informed consent to participate in our research, and the data were masked during the study. The study protocol was approved by the Ethics Committee of the University of the Ryukyus.

\section{Assessments}

The brief version of the TEMPS-A for affective temperaments [8] and the isolation-esoteric-rigidity subscales of the MPT for non-affective temperaments [9] were administered to the aforementioned 278 healthy volunteers. The TEMPS-A consists of 39 questions for cyclothymic, hyperthymic, irritable, anxious, and depressive temperaments, while the MPT contains 16 questions on schizoid and melancholic temperaments. The reliability and validity of the Japanese versions of the TEMPS-A and MPT have already been established [12, 13]. Both scales were scored using four levels: "Not true" (0), "Unlikely true" (1), "Likely true" (2) and "Completely true" (3). 
Distributions of dominant temperaments were expressed as the proportions of subjects with temperamental scores greater than the mean $+2 \mathrm{SD}$ (extremely dominant) or between the mean $+\mathrm{SD}$ and mean + 2SD (moderately dominant) (Table 1).

\section{Statistical analyses}

Data were analyzed using nonparametric statistics. The Spearman rank test was used to analyze the relationship between age and each TEMPS-A/MPT temperamental score. Gender differences in the temperament profiles were examined using the Mann-Whitney U test.

A two-tailed $p$ value of 0.05 or less was regarded as statistically significant. SPSS 11.0.1 J for Windows (SPSS Japan Inc., Tokyo, Japan) was used for these statistical analyses.

Table 1. Distributions of dominant temperaments in 278 non-clinical subjects

\begin{tabular}{lccc}
\hline & \multicolumn{2}{c}{ Number of subjects (percentage) } \\
\cline { 2 - 4 } & $>$ Mean+2SD & @Mean+2SD, > Mean+SD \\
\hline Cyclothymic (C) & $10(3.6 \%)$ & $36(12.9 \%)$ \\
Hyperthymic (H) & 5 & $(1.8 \%)$ & $39(14.0 \%)$ \\
Irritable (I) & 8 & $(2.9 \%)$ & $27(9.7 \%)$ \\
Anxious (A) & 8 & $(2.9 \%)$ & $40(14.4 \%)$ \\
Schizoid (S) & $10(3.6 \%)$ & $21(7.6 \%)$ \\
Melancholic (M) & 7 & $(2.5 \%)$ & $27(9.7 \%)$ \\
Depressive (D) & $17(6.1 \%)$ & $25(9.0 \%)$ \\
Bipolar components (C+H+I) & 7 & $(2.5 \%)$ & $33(11.9 \%)$ \\
Depressive components (C+D+A) & 8 & $(2.9 \%)$ & $31(11.2 \%)$ \\
Adaptive components (H+M) & 8 & $(2.9 \%)$ & $32(11.5 \%)$ \\
Maladaptive components (I+S) & $10(3.6 \%)$ & $27(9.7 \%)$ \\
\hline
\end{tabular}
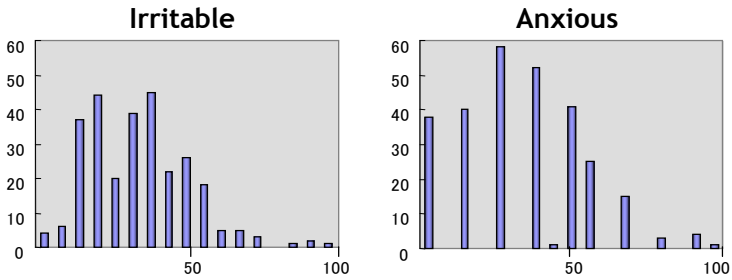

Cyclothymic

Depressive
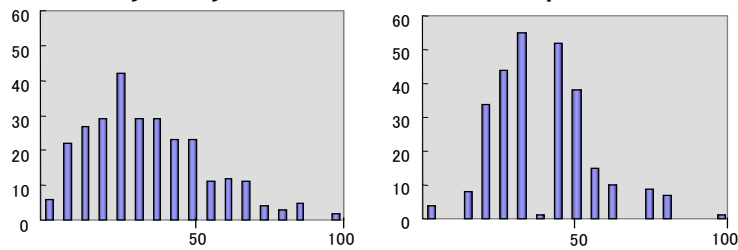

Hyperthymic
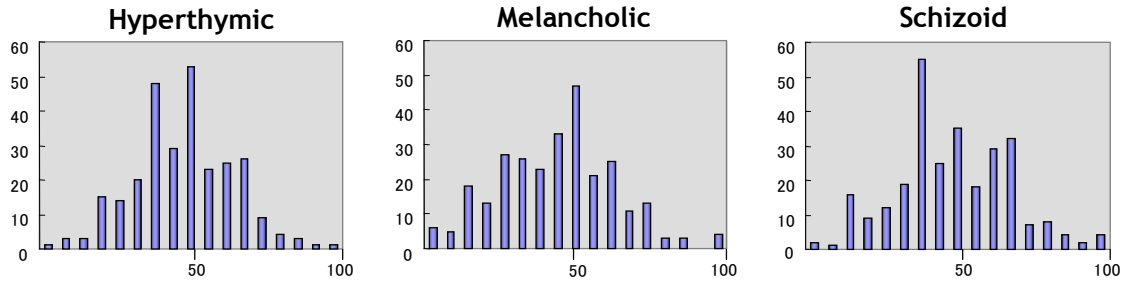

Figure 1. Histogram for scores of temperaments. The ordinate indicates the number of subjects while the abscissa indicates each temperamental score expressed as a percentage. Normal distributions were found in hyperthymic, melancholic and schizoid temperaments (lower figures). Skewed distributions in cyclothymic and depressive temperaments (middle figures) and downward distributions in irritable and anxious temperaments (upper figures) were observed. 


\section{RESULTS}

\section{Distributions of dominant temperaments}

The proportions of dominant temperaments $(>$ mean + 2SD) were $6.1 \%$ for depressive, $3.6 \%$ for cyclothymic and schizoid, $2.9 \%$ for irritable and anxious, $2.5 \%$ for melancholic, and $1.8 \%$ for hyperthymic, while those between the 1st and 2nd $\mathrm{SD}(\leq$ mean $+2 \mathrm{SD},>$ mean $+\mathrm{SD})$ were much higher, especially for the anxious and hyperthymic temperaments (Table 1). The proportion of dominance $(>$ mean $+2 \mathrm{SD})$ was $2.5-3.6 \%$ in such temperamental combinations as bipolar, depressive, adaptive and maladaptive components.

The following three distribution patterns were observed in scores of temperaments: normal distribution in hyperthymic, melancholic and schizoid temperaments; skewed distribution in cyclothymic and depressive temperaments; and downward distribution in irritable and anxious temperaments (Fig.1).

\section{Effects of age and gender}

Age was moderately correlated with cyclothymic temperament $(\mathrm{rs}=-0.355, \mathrm{p}=0.001)$ and weakly correlated with melancholic ( $\mathrm{rs}=-0.186, \mathrm{p}=0.005)$, depressive $\mathrm{rs}=-0.177, \mathrm{p}=0.003$ ) and irritable ( $\mathrm{rs}=$ $-0.139, \mathrm{p}=0.021)$ temperaments, all of which were inverse correlations (Table 2).

Females were more likely to have cyclothymic (31.8 \pm 19.6 vs. $27.1 \pm 17.3: \mathrm{p}=0.046)$ and anxious (35.3 \pm 22.5 vs. $25.9 \pm 19.1: \mathrm{p}=0.001)$ temperaments than males (Table 3). On the other hand, males had higher scores in hyperthymic $(43.5 \pm 13.9$ vs. $35.6 \pm 12.9$ : $\mathrm{p}=0.001)$ and schizoid (37.1 \pm 15.1 vs. $33.2 \pm 16.0$ : $\mathrm{p}=0.019$ ) temperaments than females (Table 3 ).

\section{Correlations among temperaments}

Strong correlations were found among four temperaments: the cyclothymic, irritable, depressive and schizoid temperaments (Fig. 2: rs $>0.5$, except for 0.435 for the correlation between the schizoid and depressive temperaments; $p=0.000001$ ). Meanwhile, the hyperthymic, anxious, and melancholic temperaments had modest satellite linkages with these four core temperaments (Fig. 2).

Although most of the temperaments correlated well with each other, no significant relationships were found between the hyperthymic and anxious, hyperthymic and depressive, or schizoid and anxious temperaments.

Table 2. The effect of age on temperament profiles (Spearman rank correlation)

Cyclothymic Hyperthymic Irritable Anxious Schizoid Melancholic Depressive

\begin{tabular}{llllllll}
\hline & & & & & & & \\
rs & -0.355 & 0.073 & -0.139 & -0.102 & -0.117 & -0.186 & -0.177 \\
$\mathrm{p}$ & 0.001 & 0.229 & 0.021 & 0.089 & 0.051 & 0.005 & 0.003 \\
\hline
\end{tabular}

Table 3. The effect of gender on temperament profiles (Mann-Whitney U test)

\begin{tabular}{lccc}
\hline & $\begin{array}{c}\text { Males } \\
(\mathrm{n}=154)\end{array}$ & $\begin{array}{c}\text { Females } \\
(\mathrm{n}=124)\end{array}$ & $\mathrm{p}$ \\
\hline Cyclothymic & $27.1 \pm 17.3$ & $31.8 \pm 19.6$ & 0.046 \\
Hyperthymic & $43.5 \pm 13.9$ & $35.6 \pm 12.9$ & 0.001 \\
Irritable & $27.1 \pm 15.1$ & $28.0 \pm 16.1$ & 0.807 \\
Anxious & $25.9 \pm 19.1$ & $35.3 \pm 22.5$ & 0.001 \\
Schizoid & $37.1 \pm 15.1$ & $33.2 \pm 16.0$ & 0.019 \\
Melancholic & $42.9 \pm 15.6$ & $43.0 \pm 15.0$ & 0.944 \\
Depressive & $30.0 \pm 14.1$ & $31.0 \pm 14.8$ & 0.736 \\
\hline
\end{tabular}

Temperament scores are expressed as percentages ( $100 \%$ indicates a perfect score) 


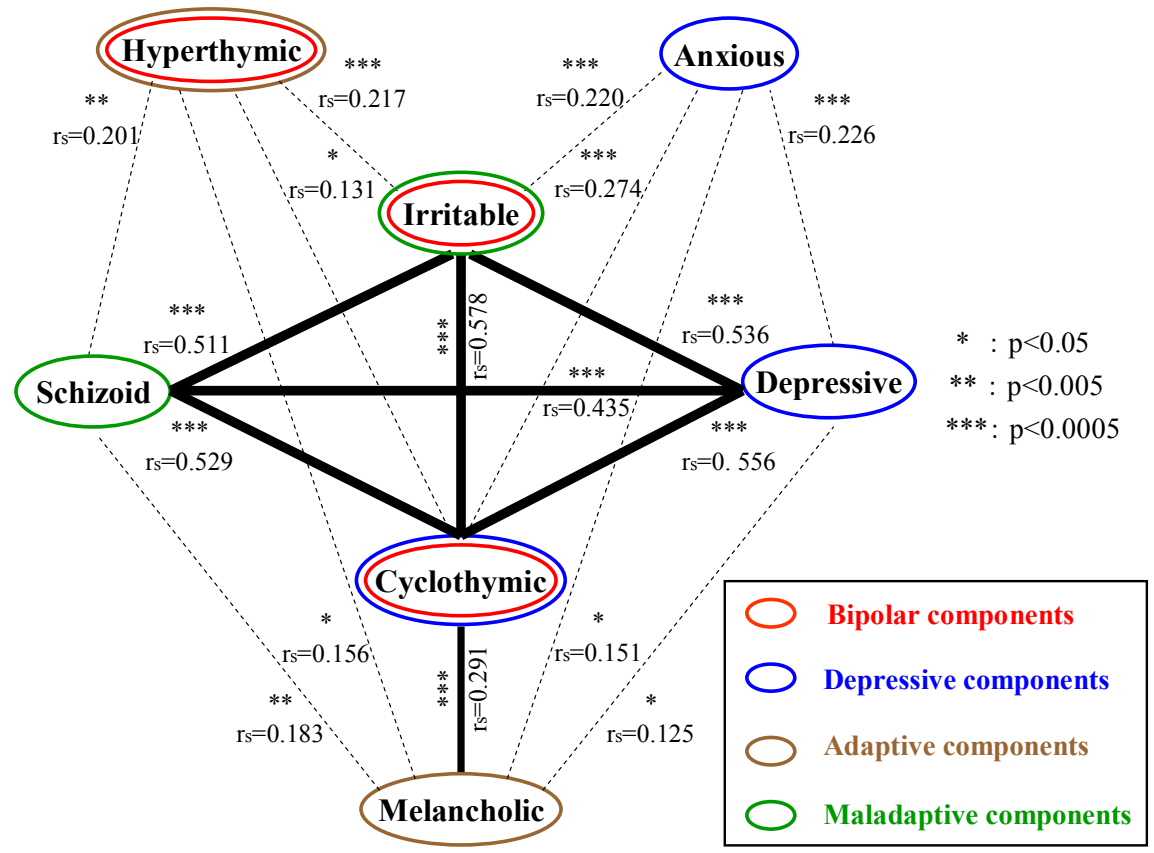

Figure 2. Correlations among temperaments assessed by the Temperament Evaluation of Memphis, Pisa, Paris and San Diego-autoquestionnaire (TEMPS-A) and the Munich Personality Test (MPT) in 278 nonclinical Japanese subjects.

\section{DISCUSSION}

The present study demonstrated that there is more dominancy (above the mean $+2 \mathrm{SD}$ ) in depressive (6.1\%) and cyclothymic (3.6\%) temperaments, and less dominancy in hyperthymic temperaments (1.8\%) among Japanese subjects, which was consistent with the pattern in the general population in other countries [14-17]. Differences in the distributions of the temperaments in Japanese subjects can be also explained by the findings of Matsumoto and colleagues [13], who reported a normal distribution in depressive temperament, a positively skewed distribution in hyperthymic temperament, and a downward distribution in cyclothymic, irritable, and anxious temperaments. The present study confirmed that the irritable and anxious temperaments have less in common and newly demonstrated that the melancholic and schizoid temperaments have normal distributions (Fig. 1). Although this may be a rough estimation, we can assume that each temperament has around $3 \%$ of extreme dominancy (over + 2SD) followed by around $10 \%$ of moderate dominancy (between 1 st and 2nd SD) in Japanese subjects (Table 1).

Inverse correlations between age and several affective personality traits suggest that younger subjects are more greatly affected by cyclothymic, melancholic, depressive and anxious temperaments (Table 2). In particular, more cyclothymic temperaments among young people may result in a higher prevalence of potential bipolarity in the younger generation. Meanwhile, it has also been pointed out that an extremely high proportion $(90 \%)$ of nonviolent suicide attempters have some kind of dominant affective temperaments, including cyclothymic, depressive, anxious and irritable traits [18]. This may partly explain the high risk of antidepressant-induced activation syndrome and the susceptibility to increased suicidality during antidepressant treatment in adolescent subjects with unstable affective temperaments [19].

The present study revealed significant gender differences in temperamental profiles, indicating that females were more likely to have cyclothymic and anxious temperaments while males were more likely to have hyperthymic and schizoid temperaments (Table 3). A higher incidence of hyperthymic temperament in males and of cyclothymic-anxious temperaments in females appear to be genderspecific and highly reproducible findings, as suggested by previous reports $[14,16,20]$. On the other hand, this study is the first to show that males are more likely to have a schizoid temperament. A higher incidence of cyclothymic temperament in females may be associated with the fact that women have a higher incidence of mood disorders, including 
bipolar disorders [21]. These gender differences in temperament profiles may result in differences in expressed psychopathology or applied psychotherapy between males and females.

Although factor analysis using the TEMPS-A/MPT validated that multiple temperaments existed independently [12], in recent studies [13, 17, 20], including ours, it has also finally been clarified that one temperament has multiple linkages with other temperaments. In particular, strong correlations were observed among the cyclothymic, irritable, depressive, and schizoid temperaments in the present study (Fig. 2). Previous reports have also suggested significant associations among such affective traits as cyclothymic, irritable, and depressive temperaments $[13,17,20]$. However, the present study clearly shows that the schizoid temperament has positive correlations with affective temperaments. It is surprising that a close association exists between the schizoid and cyclothymic temperaments, two distinct traits proposed by Kretchmer [10]. The combination of schizoid and mood dysregulation temperaments can affect psychopathology to some extent in depressed subjects, who may become progressively more isolated, avoidant, and uncooperative during mood episodes than those having less schizoid temperament. This should be taken into consideration, especially when treating male patients, who are likely to have more schizoid temperament. Accordingly, individualized treatment strategies should be implemented depending on the individual's psychopathology, which could be affected by combined traits rather than a single temperament.

Although there have been no definite categories for combined temperaments, the following components are hypothesized to try to better understand some specific temperamental combinations associated with potential bipolarity, mood dysregulation, adaptive capability and maladaptive characteristics: bipolar, depressive, adaptive and maladaptive components (Table 1, Fig.2). Cyclothymic [22-26], hyperthymic $[23,26]$, and irritable $[25,26]$ temperaments have been regarded as bipolarity-associated traits. Cyclothymic temperament $[23,27,28]$ has been also recognized as a premorbid trait for unipolar depression, as have depressive [23, 27] and anxious $[23,27,29]$ temperaments. These affective components of combined temperaments may help clinicians to make decisions on the appropriate use of antidepressants and/or mood stabilizers.

Hyperthymic temperament is known to not be closely correlated with other affective temperaments [30], and seems more characteristic of normal subjects than mood disorder patients [31]. The present study showed that hyperthymic temperament was completely independent of depressive and anxious temperaments. This temperament was also reported to be associated with persistence but not with neuroticism [14]. Furthermore, resilience in the face of various job stressors with hyperthymic temperament, followed by melancholic temperament, may suggest that hyperthymic temperament represents a "supernormal" personality and "hyperadjusted" work behavior [32]. A recent finding has supported a specific association between melancholic and hyperthymic temperaments, both of which are independent of unstable affective predispositions [33], so these temperaments can be categorized into adaptive profiles.

Both schizoid and irritable temperaments represent maladaptive components that may result in poor interpersonal skills and social adjustment. The former has static/independent characteristics while the latter has a reactive/unstable profile. A previous study suggested that schizoid personality trait is independent of mood dysregulation, which the TEMPS-A measures [12]. Similarly, irritable temperament was less involved in premorbid traits for unipolar and bipolar mood disorders than depressive, cyclothymic, and anxious temperaments [13]. These findings suggest that schizoid and irritable temperaments do not directly predispose people to mood disorders. However, these temperaments may serve as important predictors of maladaptive manifestations, including isolated and dysphoric behaviors, during mood episodes.

The 55-item TEMPS-A/MPT may be a useful pretreatment tool for the screening of baseline temperaments since this autoquestionnaire may help promote the rapid assessment of premorbid traits without a time-consuming interview process. Therefore, the use of the TEMPS-A/MPT as a quick finder for individualized treatments, including those targeting soft bipolarity, could be beneficial in the clinical setting, although we need to be cautious when interpreting and applying the TEMPS-A/MPT results when deciding on an optimal treatment.

This study is still preliminary and has several limitations: the relatively small sized, the lack of inclusion of clinical subjects, and the absence of random sample collection. However, the present study has yielded background data on premorbid temperaments in non-clinical Japanese subjects and 
suggests that the use of the TEMPS-A/MPT in the usual clinical setting may be indicated. Larger-sized studies that include clinical subjects will more clearly reveal the necessity of pretreatment assessments of temperaments for rational pharmacotherapy and psychotherapy in patients with mood disorders.

\section{CONCLUSION}

Close correlations among temperaments suggest that individualized treatment strategies should be undertaken based on the psychopathology of the individual, which is possibly affected by combined temperaments. Young and female individuals are more likely to have cyclothymic temperaments, suggesting that these subjects may have a higher prevalence of bipolarity.

\section{ACKNOWLEDGEMENTS}

This study was supported by a Grant-in Aid from the Japanese Ministry of Education, Culture, Sports, Science and Technology (\#19591366). We would like to express our sincerest gratitude to Dr. Tsuyoshi Akiyama (Department of Neuropsychiatry, Kanto Medical Center NTT EC, Tokyo) for generously providing the Japanese version of the TEMPS-A/ MPT. We would also like to thank Mr. Singeru Travis Singeo Jr. for his helpful advice.

\section{REFERENCES}

[1] American Psychiatric Association. Diagnostic and Statistical Manual of Mental Disorders. 4th edition, text version (DSM-IV-TR), American Psychiatric Association, Washington, DC, 2000.

[2] World Health Organization. The ICD-10 classification of mental and behavioural disorders. World Health Organization, Geneva, 1992.

[3] Akiskal HS. The bipolar spectrum: New concepts in classification and diagnosis. In Grinspoon L (ed) Psychiatry update: The American Psychiatric Association annual interview. American Psychiatric Press, Washington DC , 1983, pp.271-292.

[4] Akiskal HS, Bourgeois ML, Angst J, Post R, Möller H-J, Hirschfeld R. Re-evaluating the prevalence of and diagnostic compositions within the broad clinical spectrum of bipolar disorders. J Affect Disord 2000; 59: S5-S30.

[5] Ghaemi SN, Ko JY, Goodwin FK. The bipolar spectrum and the antidepressant view of the world. J Psychiatr Pract 2001; 7: 287-297.

[6] Kraepelin E. Psychiatrie: EinLehrbuch für Studierende und Ärzte, Achte Auflage, Johann Ambrosius Barth, Leipzig, 1913.

[7] Akiskal HS, Akiskal KK, Haykal RF, Manning JS, Connor PD. TEMPS-A: progress towards validation of a self-rated clinical version of the Temperament Evaluation of the Memphis, Pisa, Paris, and San Diego Autoquestionnaire. J Affect Disord 2005; 85: 3-16.

[8] Akiskal HS, Mendlowicz MV, Jean-Louis G, Rapaport MH, Kelsoe JR, Gillin JC, Smith TL. TEMPS-A: validation of a short version of a self-rated instrument designed to measure variations in temperament. $\mathrm{J}$ Affect Disord 2005; 85: 45-52.

[9] Von Zerssen D, Pfister H, Koeller DM. The Munich Personality Test (MPT) - a short questionnaire for self-rating and relatives' rating of personality traits: formal properties and clinical potential. Eur Arch Psychiatry Neurol Sci 1988; 238: 73-93.

[10] Kretchmer E. Körperbau und Charakter. 21 und 22 Auflage. Springer, Berlin, 1955.

[11] Tellenbach H. Melancholie. Springer, Berlin, 1961.

[12] Akiyama T, Tsuda H, Matsumoto S, Miyake Y, Kawamura Y, Noda T, Akiskal KK, Akiskal HS. The proposed factor structure of temperament and personality in Japan: combining traits from TEMPS-A and MPT. J Affect Disord 2005; 85: 93-100.

[13] Matsumoto S, Akiyama T, Tsuda H, Miyake Y, Kawamura Y, Noda T, Akiskal KK, Akiskal HS. Reliability and validity of TEMPS-A in a Japanese non-clinical population: application to unipolar and bipolar depressives. J Affect Disord 2005; 85: 85-92.

[14] Rózsa S, Rihmer Z, Gonda X, Szili I, Rihmer A, Ko N, Németh A, Pestality P, Bagdy G, Alhassoon O, Akiskal KK, Akiskal HS. A study of affective temperaments in Hungary: internal consistency and concurrent validity of the TEMPS-A against the TCI and NEO-PI-R. J Affect Disord 2008; 106: 45-53.

[15] Pompili M, Girardi P, Tatarelli R, Iliceto P, De Pisa E, Tondo L, Akiskal KK, Akiskal HS. TEMPS-A (Rome): psychometric validation of affective temperaments in clinically well subjects in mid- and south Italy. J Affect Disord 2008; 107: 63-75.

[16] Borkowska A, Rybakowski JK, Drozdz W, 
Bielinski M, Kosmowska M, Rajewska-Rager A, Bucinski A, Akiskal KK, Akiskal HS. Polish validation of the TEMPS-A: The profile of affective temperaments in a college student population. J Affect Disord 2010; 123: 36-41.

[17] Preti A, Vellante M, Zucca G, Tondo L, Akiskal K, Akiskal H. The Italian version of the validated short TEMPS-A: the temperament evaluation of Memphis, Pisa, Paris and San Diego. J Affect Disord 2010; 120: 207-212.

[18] Rihmer A, Rozsa S, Rihmer Z, Gonda X, Akiskal KK, Akiskal HS. Affective temperaments, as measured by TEMPS-A, among nonviolent suicide attempters. J Affect Disord 2009; 116:18-22.

[19] Goodman WK, Murphy TK, Storch EA. Risk of adverse behavioral effects with pediatric use of antidepressants. Psychopharmacology 2007; 191: 87-96.

[20] Figueira ML, Caeiro L, Ferro A, Severino L, Duarte PM, Abreu M, Akiskal HS, Akiskal KK. Validation of the Temperament Evaluation of Memphis, Pisa, Paris and San Diego (TEMPS-A): Portuguese-Lisbon version. J Affect Disord 2008; 111: 193-203.

[21] Kennedy N, Boydell J, Kalidindi S, Fearon P, Jones PB, van Os J, Murray RM. Gender differences in incidence and age at onset of mania and bipolar disorder over a 35-year period in Camberwell, England. Am J Psychiatry. 2005; 162: 257-262.

[22] Benazzi F. Cyclothymic temperament: the impact of age. Psychopathology 2009; 42: 165-169.

[23] Mazzarini L, Pacchiarotti I, Colom F, Sani G, Kotzalidis GD, Rosa AR, Sanna L, De Rossi P, Girardi N, Bonnin CM, Sanchez-Moreno J, Vazquez GH, Gasto C, Tatarelli R, Vieta E. Predominant polarity and temperament in bipolar and unipolar affective disorders. $\mathrm{J}$ Affect Disord 2009; 119: 28-33.

[24] Camacho A, Akiskal HS. Proposal for a bipolar-stimulant spectrum: temperament, diagnostic validation and therapeutic outcomes with mood stabilizers. J Affect Disord 2005; 85: 217-230.

[25] Röttig D, Röttig S, Brieger P, Marneros A. Temperament and personality in bipolar I patients with and without mixed episodes. J Affect Disord 2007; 104: 97-102.

[26] Ozgürdal S, van Haren E, Hauser M, Ströhle A, Bauer M, Assion HJ, Juckel G. Early mood swings as symptoms of the bipolar prodrome: preliminary results of a retrospective analysis. Psychopathology 2009;42(5):337-342.

[27] Lazary J, Gonda X, Benko A, Gacser M, Bagdy G. Association of depressive phenotype with affective family history is mediated by affective temperaments. Psychiatry Res 2009; 168: 145-152.

[28] Maina G, Salvi V, Rosso G, Bogetto F. Cyclothymic temperament and major depressive disorder: A study on Italian patients. J Affect Disord 2010; 121: 199-203.

[29] Savitz J, van der Merwe L, Ramesar R. Dysthymic and anxiety-related personality traits in bipolar spectrum illness. J Affect Disord 2008; 109: 305-311.

[30] Akiskal HS, Placidi GF, Signoretta S, Liguori A, Gervasi R, Maremmani I, Mallya G, Puzantian VR. TEMPS-I: delineating the most discriminate traits of cyclothymic, depressive, irritable and hyperthymic temperaments in a nonpatient population. J Affect Disord 1998; 51: 7-19.

[31] Akiyama T, Tsuda H, Matsumoto S, Kawamura Y, Miyake Y. Cyclothymia and typus melancholicus: empirical study on personality character of mood disorder. Psychiatr Neurol Jpn 2003; 105: 533-543.

[32] Sakai Y, Akiyama T, Miyake Y, Kamura Y, Tsuda H, Kurabayashi L, Tominaga M, Noda T, Akiskal K, Akiskal H. Temperament and job stress in Japanese company employees. J Affect Disord 2005; 85: 101-112.

[33] Stanghellini G, Raballo A. Exploring the margins of the bipolar spectrum: temperamental features of the typus melancholicus. $J$ Affect Disord 2007; 100: 13-21. 